\title{
Pulsatile flow simulation of patent ductus arteriosus to evaluate thrombosis factors on closure device
}

\author{
Nurulnatisya Ahmad a, Ishkrizat Taib b, Kahar Osman c,d, Ahmad Zahran Md Khudzari c,d,* \\ a Faculty of Mechanical Engineering, Universiti Teknologi MARA, UiTM Cawangan Johor, Kampus Pasir Gudang, Masai, 81750, Johor, Malaysia \\ b Faculty of Mechanical and Manufacturing Engineering, Universiti Tun Hussein Onn, Parit Raja Batu Pahat, 86400, Johor, Malaysia \\ c IJN-UTM Cardiovascular Engineering Centre, Institute of Human Centered Engineering, Universiti Teknologi Malaysia, 81310 UTM Johor Bahru, \\ Johor, Malaysia \\ d Faculty of Biosciences and Medical Engineering, Universiti Teknologi Malaysia, 81310 UTM Johor Bahru, Johor, Malaysia \\ *Correspondence: zahran.kl@utm.my
}

\section{Article history}

Received 21 November 2017

Accepted 6 December 2017

\begin{abstract}
Transcatheter treatment using occlusion devices is the most common treatment used to treat the Patent Ductus Arteriosus (PDA). The occlusion device act as a physical barrier to blood flow in the duct which facilitates thrombogenesis and occludes the duct. Over the past 15 years, there have been significant developments in the devices used to close PDA. Various design of occlusion device affects the flow of blood in the duct. To improve the efficiency of the thrombogenesis on the surface of occlusion device and estimate the time needed to occludes the duct, it is important to simulate blood flow through different design of occlusion device. Two design was used which is the concave and convex shape of the occlusion device. Blood was simulated as Newtonian with the incompressible and laminar flow. A computational fluid dynamics (CFD) study has been done in pulsatile blood flow through the aortic arch and the occlusion device. The hemodynamic parameters that contribute to the thrombosis formation have been studied and showed that the convex shape yielded more TAWSS Iow $_{\text {I }}$ $(<0.5 \mathrm{~Pa})$ magnitude $(65.72 \%)$, generated $51.84 \%$ areas that exposed to high OSI and calculated $14.46 \%$ areas that exposed to RRT $\geq 10 \mathrm{~Pa}^{-1}$. While, concave shape yielded $13.21 \%$ of TAWSS $0.5 \mathrm{~Pa}$ ), generated only $47.84 \%$ of areas that exposed to high OSI and calculated $14.46 \%$ areas that exposed to RRT $\geq 10 \mathrm{~Pa}^{-1}$. Therefore, from the preliminary work on PDA occlusion device, it is suggested that to promote thrombosis, the convex shape was much better compared to concave shape.
\end{abstract}

Keywords: Patent ductus arteriosus, flow analysis, CFD, thrombosis, closure devices, haemodynamic

\section{INTRODUCTION}

Congenital Heart Defects (CHD) is an abnormality in heart structure present since birth. With this condition, some part of the heart does not form properly. This will change the normal flow of the blood through the heart. There are many types of congenital heart defects. Patent Ductus Arteriosus (PDA) is one of the common heart defects that can occur soon after birth (Figure 1.). In children who were born at term, the incidence of PDA has been reported to be roughly 1 in 2000 births (S. Liddy et al., 2013 and T. Forbes et al., 2012). PDA accounts for around $5 \%$ to $10 \%$ of all congenital heart defects and is a common problem occurred in preterm infants (Benitz W. E. and Committee on Fetus and Newborn, 2016). In PDA, it contributes to abnormal blood flow between two major arteries in the heart which is aorta and pulmonary artery. Before birth, these arteries were connected by a blood vessel called ductus arteriosus as an essential part of fetal blood circulation. The ductus arteriosus should be close right after birth.

However, if the duct stays open, it will allow oxygen-rich blood from the aorta to mix with oxygen-poor blood from the pulmonary artery. This can strain the heart and increase blood pressure in the lung arteries. In order to meet body oxygen demand, the heart is going to have to pump more blood to cover what circulates in the shunt as well as what the body needs. Therefore, extra work needed for the heart and failure can result, leading to coughing, weakness, and difficulty of breathing. If the size of the PDA is too large, it also can cause death and heart failure. These effects due to the irregularity of the blood transmission occur since the oxygenated blood from the aorta and the deoxygenated blood is mixing.

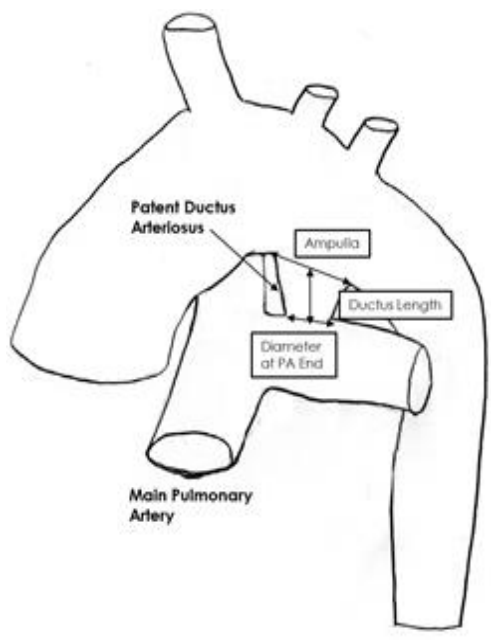

Fig. 1 Patent Ductus Arteriosus (PDA). 
There are few ways to treat this PDA, patients might take medicines, undergo surgery or using the catheter-based procedure. The most popular treatment is using the catheter since it takes a shorter time to recover and will not left scars on the chest. A closure medical device will be implanted into the patient by using a surgical method or by using transcatheter device. From 1967, Porstmann's first publication according to the non-surgical transcatheter closure was generally accepted by the public from all over the world. Through the years, there are many design of non-surgical devices that had been used such as Raskind's umbrella, Sideris buttoned device, Embolization coils and Amplatzer Duct Occluder (ADO). Amplatzer Duct Occluder (ADO) is the first device approved specifically for the treatment of PDAs (Moore JW et al., 2005).

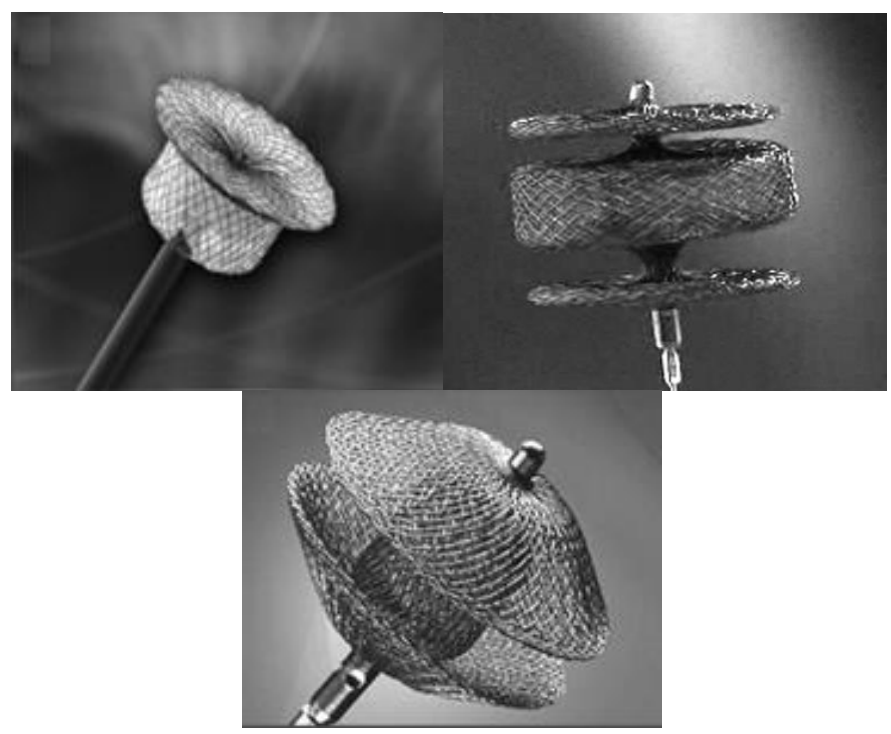

Fig. 2 (a) Amplatzer duct occluder device (AGA Medical Corporation, Plymouth, MN) (b) Amplatzer Vascular Plug II (AGA Medical Corporation, Plymouth, MN) (c) Amplatzer PDA Duct Occluder II (AGA Medical Corporation, Plymouth, MN). (Douglas J et al., 2012).

The basic principle of occlusion or closure involves introducing a physical barrier to flow of blood in the duct, which is done by implanting the device in the duct. Besides acting as a physical barrier, the device also facilitates the process of thrombosis. The mechanism of occlusion of the PDA is thrombosis formation around the materials of the devices, followed by neo-endothelial growth and cellular organization of the thrombotic material (Yingying $\mathrm{H}$ et al., 2014). The device will cause arterial injury by damaging the endothelial cells. The damaged parts of the artery will attract the blood-borne platelets to the source of arterial injury around the device. The platelets are then transported to the injury side via the blood flow where they adhere to the damaged cells and then release the chemical attractants for the platelets. A stringy protein called fibrin then will be formed around the platelets to bind them together into a thrombus. The formation of a thrombus is known begins immediately after implanting the occlusion device.

From the clinical study with the current closure device, more than $90 \%$ of patients undergo PDA operation takes more than 6 months to close the PDA after the implantation. Only about $50 \%$ of patients closed the PDA immediately after the implantation (Carlgren LE., 1959). From this study, the analysis of the hemodynamic effects can give a better explanation on the formation of the thrombosis on the PDA and predict the estimated time needed to close the PDA. Therefore, by continuing this study, analysis and comparative study of the effects of hemodynamic of different designs of closure devices will be helpful to invent an efficient closure device and less hemodynamic factors side effect to the patient of PDA.

The thrombosis occurrence is important after implanting the closure device because it will hold the device tightly and avoid the reopening of the closure device occurred. The clot, with the device in its core, acts as a natural permanent plug and effectively occludes the duct. Therefore, the thrombosis factors can be used to determine the effectiveness of the design of closure device. The low fluid velocity and the resultant low shear stress $(<0.5 \mathrm{~Pa})$ that acts on the wall can be used as the major hemodynamic factors that prone to thrombosis formation. (Asakura T et al., 1990). The thrombosis has been reported, occurred mainly due to the presence of low shear stresses. (Haruguchi $\mathrm{H}$ et al., 2003).

Various designs with several size and shape of the devices can influence the flow of the blood in the vessel. Therefore, an analysis is needed on the hemodynamic effects after implanting the device into the PDA. Two designs of closure device attached to the aorta will be simulated using computational fluid dynamic (CFD) software. This study aim was to analyze the hemodynamics flow around the proposed devices. Time average wall shear stress (TAWSS), oscillatory shear index (OSI) and relative relevance time (RRT) were used as the hemodynamics factors that are believed play a key role that affects the thrombosis formation around the devices, and thus were used as performance indexes.

It is also important for the device to be anchored firmly in position. Contact friction between device and vessel wall also plays a crucial role in anchoring the device. As compression of device increases, friction require to retain it will be decreases. Larger differential pressure and lesser compression will eventually need higher friction values to retain the device (Vaibhavi AS et al., 2016). Therefore, the size and shape of the devices play an important role in designing an effective closure devices. To improve the efficiency of the thrombogenesis on the surface of occlusion device and estimate the time needed to occludes the duct, it is important to simulate blood flow through different design of occlusion device.

\section{METHODOLOGY}

\section{Computational methods}

Computer Aided Design (CAD) software, Solidworks, was used for modeling the simplified model of the PDA. While, Computational Fluid Dynamic (CFD) analysis was used to simulate the blood flow through PDA using ANSYS 14.0 CFX (ANSYS, Inc., Canonsburg, PA, USA). The turbulence model used in this analysis was $\mathrm{k}-\mathrm{w}$ equation with additional Shear Stress Transport (SST) turbulence model. Fig. 3 shows the Grid Independence Test (GIT) analysis for the model used. In this study, the resulting 3D CFD grid had 2,217,000 uniformly spaced nodes, with an average node spacing resolution of $0.2 \mathrm{~mm}$ and the maximum skewness is 0.85 and $y$-plus $(y+)$ value less than 1 . Where, for low Renolds models and enhanced wall functions the first grid point should be close to $\mathrm{y}+=1$ (Bengt A et al., 2012).

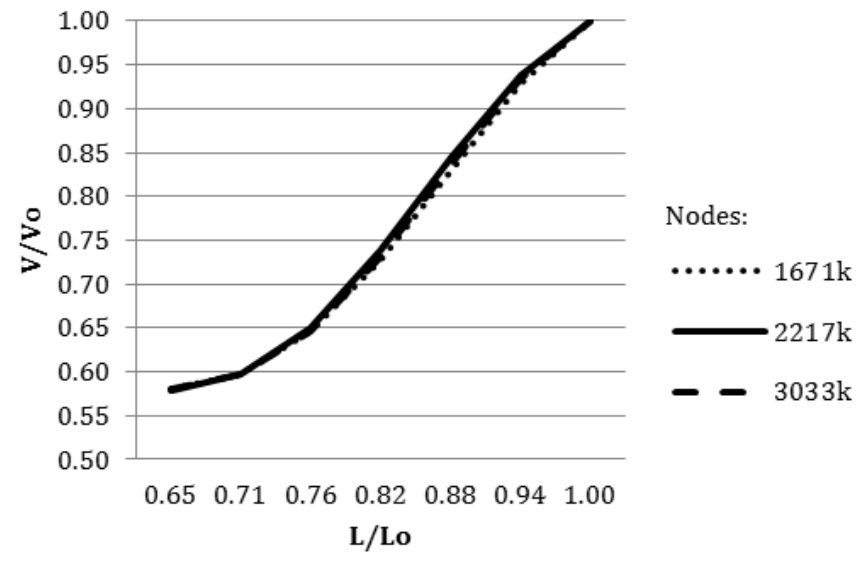

Fig. 3 Grid Independence test analysis

Fig. 4 shows the mesh model for both design of concave and convex shape attached to the simplified model of the aorta. Both models was meshed using tetrahedral method due to the unsymmetrical geometry. The simulation was done for three cycles and it takes about four to five days to complete all the three cycles for each models. 


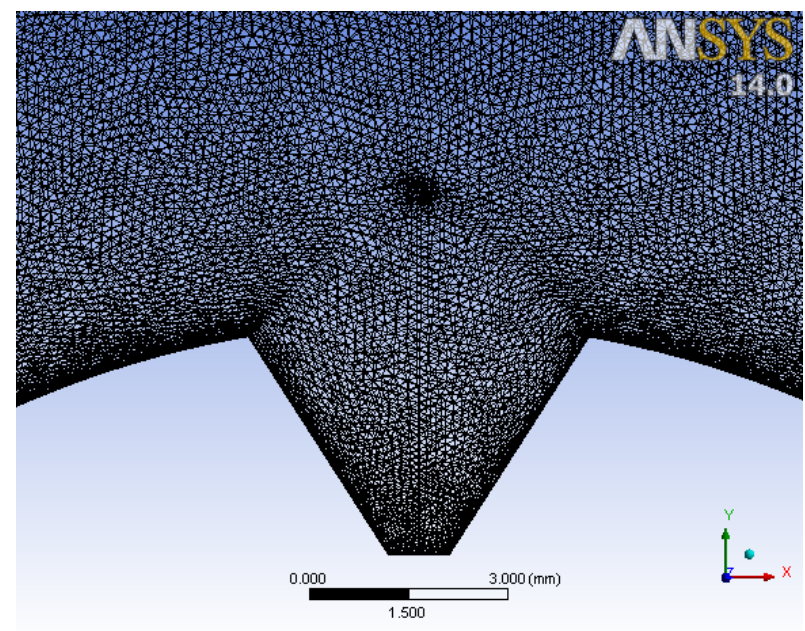

(a) Concave

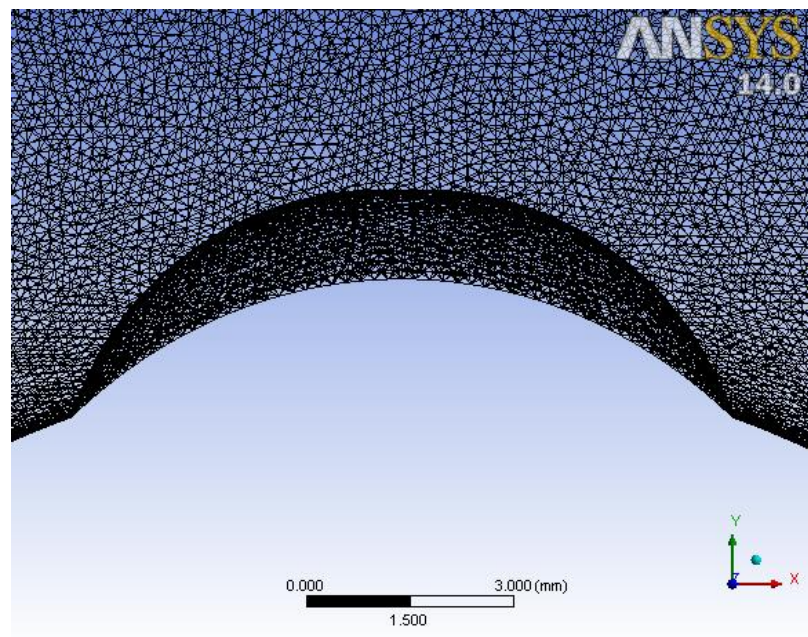

(b) Concave

Fig. 4 Mesh model for (a) convex (b) concave shape of occlusion devices

\section{Boundary conditions}

The blood was simulating incompressible, laminar and Newtonian blood flow with pulsatile nature. The constant hemodynamic properties with a density of blood, $\rho=1060 \mathrm{~kg} / \mathrm{m}^{3}$, and a dynamic viscosity, $\mu=0.00345$ Pa.s was used. Pulsatile inlet blood velocity was used at the ascending aorta for one full cardiac cycle at $0.43 \mathrm{~s}$ is given in Fig. 5. The simulations are continued for three cycles at $1.29 \mathrm{~s}$ for the flow become periodic and to disappear the start-up effects. As in the outlet vessel, zero pressure has been setup at the descending aorta.

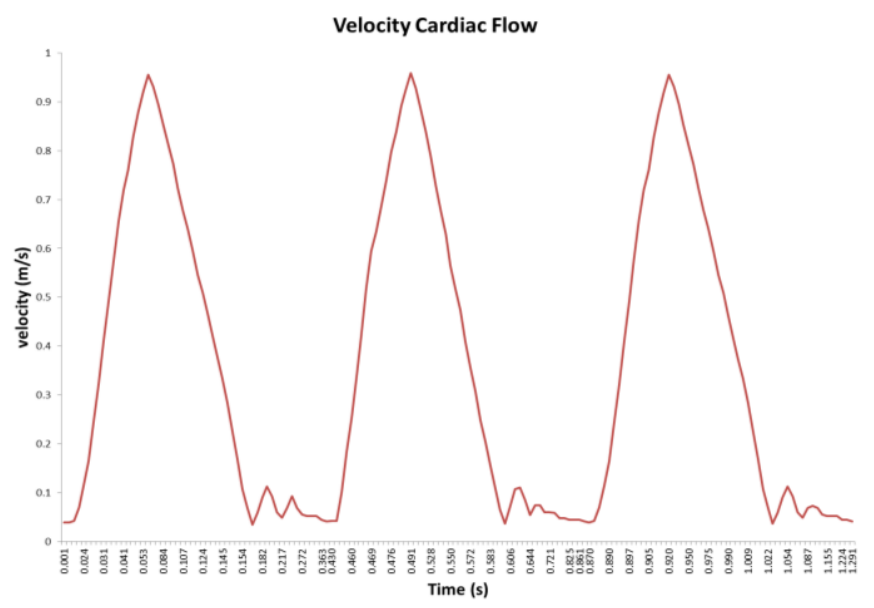

Fig. 5 Velocity Cardiac Flow (Pennati G et al., 1997)

\section{Model}

The simulations were performed for two different shapes of PDA closure device which are convex and concave shapes. Fig. 6 (a) shows a simplified model of the normal condition of the aorta with concave shape PDA closure device, while Fig. 6 (b) shows the model with convex shape PDA closure device. The dimensions of vessels are shown in Table 1.

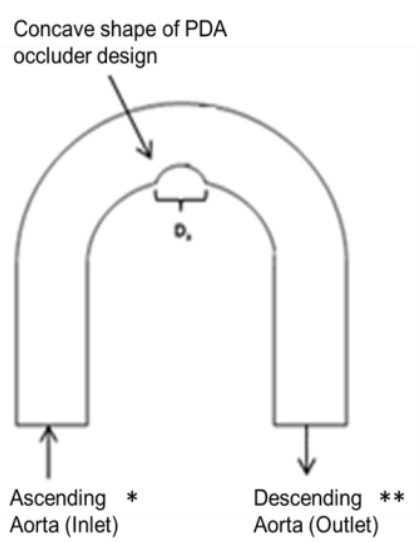

(a)

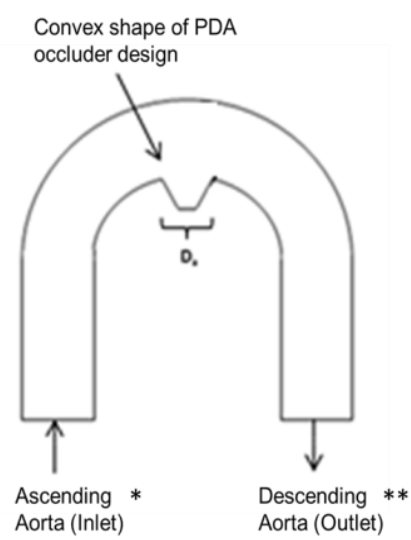

(b)
* Pulsatile blood flow inlet velocity (Fig. 5) (Ascending aorta)

** Zero pressure outlet (Descending aorta)

Fig. 6 Closure device occluded the PDA in aorta (a) Concave shape (b) Convex shape

Table 1 Dimensions of aorta and closure device.

\begin{tabular}{cc}
\hline Vessel & Dimension $(\mathbf{m m})$ \\
\hline Diameter of ascending aorta & 12 \\
Diameter of descending aorta & 12 \\
Ampulla diameter $\left(\mathrm{D}_{\mathrm{a}}\right)$ & 10 \\
\hline
\end{tabular}

\section{Hemodynamic parameters}

Several hemodynamic parameters which are, time average wall shear stress (TAWSS), oscillatory shear index (OSI) and relative relevance time (RRT) were evaluated to analyze the factors prone to thrombosis.

A transient flow model was used to generate a Time-Average Wall Shear Stress (TAWSS) map for each of the two occluder model configurations. TAWSS is the integration of each nodal WSS magnitude over the cardiac cycle. TAWSS is defined in Eq. 1.

$$
T A W S S=\frac{1}{T} \int_{0}^{T}|W S S| d t
$$

where $\mathrm{T}$ is the duration of one cardiac cycle and $d t$ is a small increment of time.

The Oscillatory Shear Index (OSI) is a dimensionless metric of changes in WSS Direction. OSI is a time-dependent quantity defined using Eq. 2.

$$
O S I=\frac{1}{2}\left(1-\frac{\left|\frac{1}{T} \int_{0}^{T} W S S d t\right|}{\frac{1}{T} \int_{0}^{T}|W S S| d t}\right)
$$

The Relative Residence Time (RRT) is inversely proportional to both TAWSS and OSI. RRT can be calculated from Eq. 3 .

$$
R R T=\frac{1}{[1-2(O S I)] T A W S S}
$$




\section{RESULTS AND DISCUSSION}

The pulsatile hemodynamic parameter is compared between the two flow models (concave and convex shape). The hemodynamic parameters that contribute to the thrombosis formation have been studied in this research that focuses on the flow around the occluder devices attached on the simplified model of the aorta. Both designs have been compared to evaluate the hemodynamics flow around the closure device to determine the effectiveness of the device on promoting thrombosis formation. Time average wall shear stress (TAWSS), oscillatory shear index (OSI) and relative relevance time (RRT) were used as the hemodynamic factors that prone to thrombosis formation.

\section{Time average wall shear stress (TAWSS)}

Fig. 7 shows the contour of time average wall shear stress (TAWSS) for both concave and convex shape of PDA closure design. The blue contour shows the low magnitude of wall shear stress. It is clearly shown in the figure that more low magnitude of TAWSS appeared on convex shape compared to the concave shape.

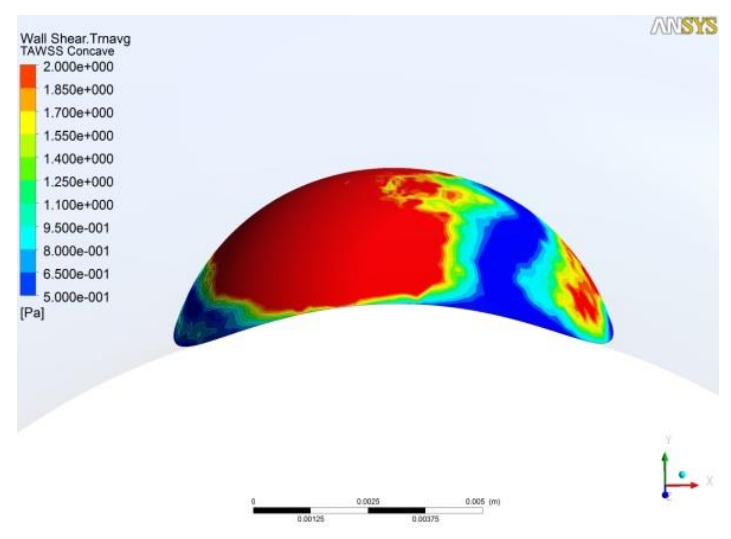

(a) Concave

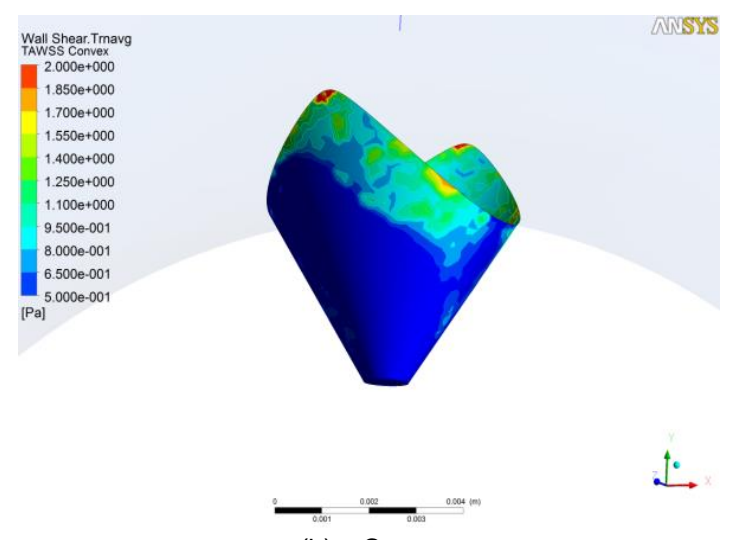

(b) Convex

Fig. 7 Time average wall shear stress (TAWSS) for both PDA closure design (a) Concave (b) Convex.

In Table 2 and Fig. 8, it is clearly shown the distribution of TAWSS data and graph comparison in concave and convex shape Convex shape contributes $65.72 \%$ of TAWSS low $<0.5 \mathrm{~Pa}, 34.16 \%$ of $0.5<$ TAWSS $<2$ and $0.12 \%$ TAWSS $>2 \mathrm{~Pa}$. While, compared to concave shape that only $13.21 \%$ of TAWSS low $_{\text {low }}<0.5 \mathrm{~Pa}$, increased to $40.25 \%$ of $0.5<$ TAWSS $<2$ and higher TAWSS $>2 \mathrm{~Pa}$ which is $46.53 \%$.

Convex shape yielded greater TAWSS Tow $(<0.5 \mathrm{~Pa})$ magnitude compared to a concave shape. Therefore, it can be suggested that the convex shape was better than concave shape; thrombosis has been reported occurring due to the presence of TAWSS low $_{\text {(Haruguchi } \mathrm{H} \text { et }}$ al., 2003). The flow recirculation zone indicated that concave shape yielded lower low time average wall shear stress (TAWSS low) magnitude compared to a convex shape. The flow recirculation zones with TAWSS low $(<0.5 \mathrm{~Pa})$ are connected with inhibition of reendothelialization, that are potential in enabling pro-coagulant and proinflammatory elements to accumulate (Juan MJ et al., 2009), which contribute to thrombosis formation.

Table 2 TAWSS Data comparison for concave and convex shape.

\begin{tabular}{lcc}
\hline $\begin{array}{l}\text { Hemodynamics } \\
\text { parameters }\end{array}$ & Concave & Convex \\
\hline TAWSS & & \\
Low $<0.5 \mathrm{~Pa}$ & $13.21 \%$ & $65.72 \%$ \\
TAWSS $>2 \mathrm{~Pa}$ & $40.25 \%$ & $34.16 \%$ \\
\hline
\end{tabular}

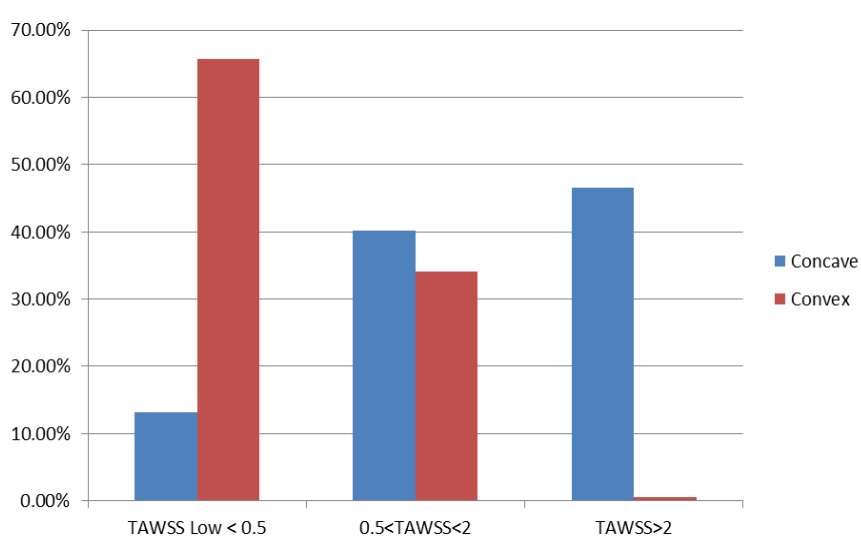

Fig. 8 Time Average Wall Shear Stress (TAWSS) graph comparison between convex and concave shape of PDA closure device.

\section{Oscillatory shear index (OSI)}

OSI value range is between 0 to 0.5 , where OSI is zero when there is no oscillatory wall shear stress and 0.5 when there is maximum oscillatory wall shear stress. In this study, the percentage of the area exposed to high OSI $\geq 0.2$ is calculated and analyzed as shown in Table 3 . From the data comparison between concave and convex shape, it shows that convex shape generated $51.84 \%$ areas that exposed to high OSI which is $4 \%$ higher than concave shape.

The oscillatory shear index (OSI) has been proposed originally to identify the regions of low oscillatory wall shear stress in carotid arteries (Ku DN et al., 1985) that would lead to the development of neointimal hyperplasia (NIH). The region of the high value of OSI tends to have a greater risk on artery deposition, which could lead the formation of atherosclerosis (Zarins C.K et al., 1983). The endothelial cell permeability and the process of cell proliferation were also observed to be increased when the OSI is higher. Therefore, in order to generate more thrombosis formation as needed in designing the occluder device, the more region of the high value of OSI is preferable. In the case of OSI, convex shape was slightly better than concave shape.

Table 3 OSI Data comparison for concave and convex shape.

\begin{tabular}{llc}
\hline $\begin{array}{l}\text { Hemodynamics } \\
\text { parameters }\end{array}$ & Concave & Convex \\
\hline $\begin{array}{l}\text { Percentage of areas } \\
\text { exposed to OSI } \geq 0.2\end{array}$ & $47.84 \%$ & $51.84 \%$ \\
\hline
\end{tabular}

Fig. 9 shows the contour of oscillatory shear index (OSI) for both concave and convex shape of PDA closure design at end of diastole of three complete cardiac cycles at $1.29 \mathrm{~s}$. The red contour shows higher magnitude of OSI. It is clearly shown in the figure that the high oscillatory wall shear stress occurred at the downstream of the concave shape. This is also shows that the flow separation was found at the downstream of concave shape. From the analysis, the design of convex shape has increased and promoted the flow separation inside the convex shape. Compared to concave shape, the streamlined shape has been reduced leading to the flow separation generated around the device. 


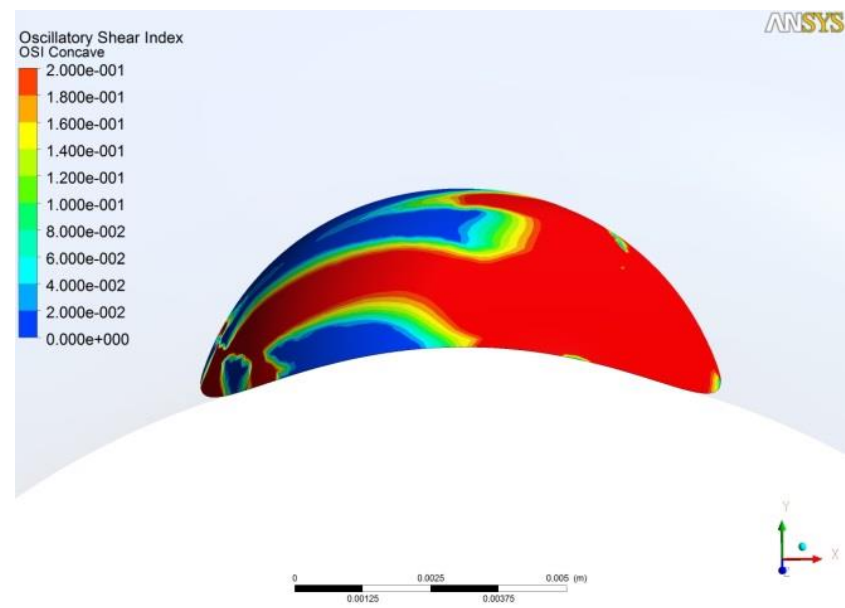

(a) Concave

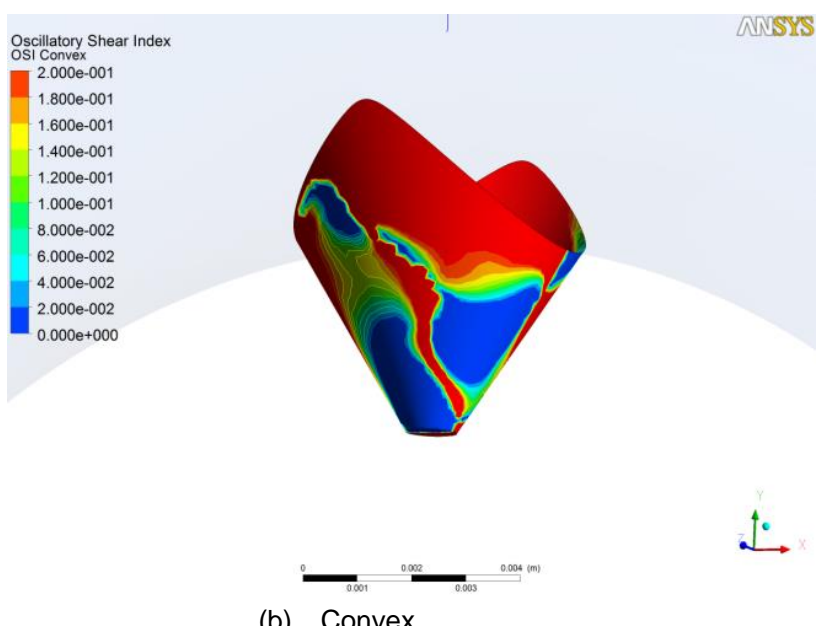

(b) Convex

Fig. 9 Time average wall shear stress (TAWSS) for both PDA closure design (a) Concave (b) Convex.

\section{Relative residence time (RRT)}

Relative residence time (RRT) is a scalar-valued quantity which combined both TAWSS and OSI in predicting time residence for stagnation flow at a certain region of the luminal surface. The value of RRT that is more or equal to $10 \mathrm{~Pa}^{-1}$ is adopted and analyzed in this study. The decrease in TAWSS would increase the RRT value otherwise increase in OSI could cause an increment of RRT. Therefore, high percentage of RRT value that is more or equal to $10 \mathrm{~Pa}^{-1}$ would increase the percentage of low wall shear stress $\left(\mathrm{TAWSS}_{\text {low }}<0.5 \mathrm{~Pa}\right)$ that has been discussed earlier would promote the thrombosis formation.

Table 4 shows the percentage of areas in wall occluder that exposed to high RRT $\geq 10 \mathrm{~Pa}^{-1}$. From the data comparison between the concave and convex shape of occluder design, it shows that convex shape calculated $14.46 \%$ areas that exposed to RRT $\geq 10 \mathrm{~Pa}^{-1}$ which is $4.56 \%$ higher than concave shape.

Table 4 RRT Data comparison for concave and convex shape.

\begin{tabular}{ccc}
\hline Hemodynamics parameters & Concave & Convex \\
\hline $\begin{array}{c}\text { Percentage of areas } \\
\text { exposed to wall occluder } \\
\text { for RRT } \geq 10 \mathrm{~Pa}^{-1}\end{array}$ & $9.90 \%$ & $14.46 \%$ \\
\hline
\end{tabular}

As in Fig. 10, it shows the contour of relative residence time (RRT) for both concave and convex shape of PDA closure design at end of diastole of three complete cardiac cycles at $1.29 \mathrm{~s}$. The figure shows that more regions of concave shape that exposed to high RRT index happened at the downstream part. Therefore, the stagnation flow was found at the downstream part of the concave shape. While for the design of convex shape it shows that high RRT index happened inside the convex shape.

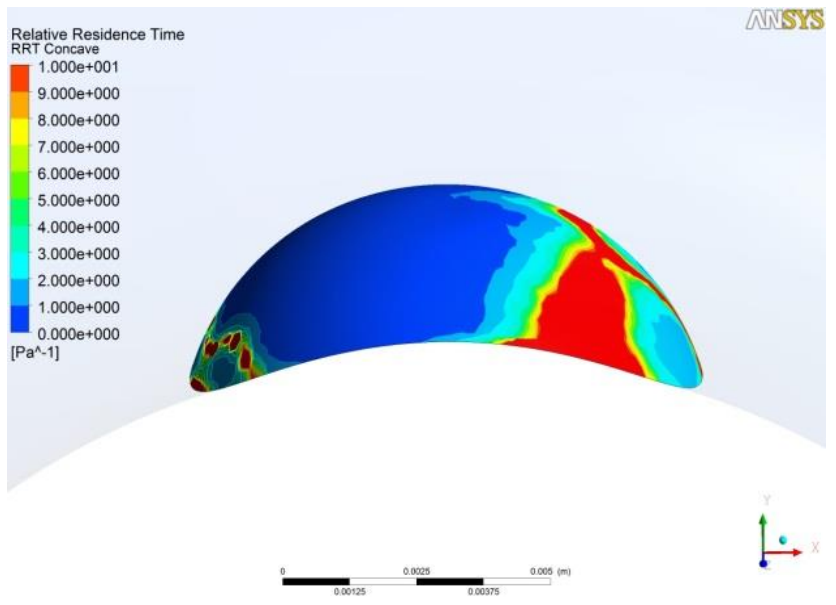

(a) Concave

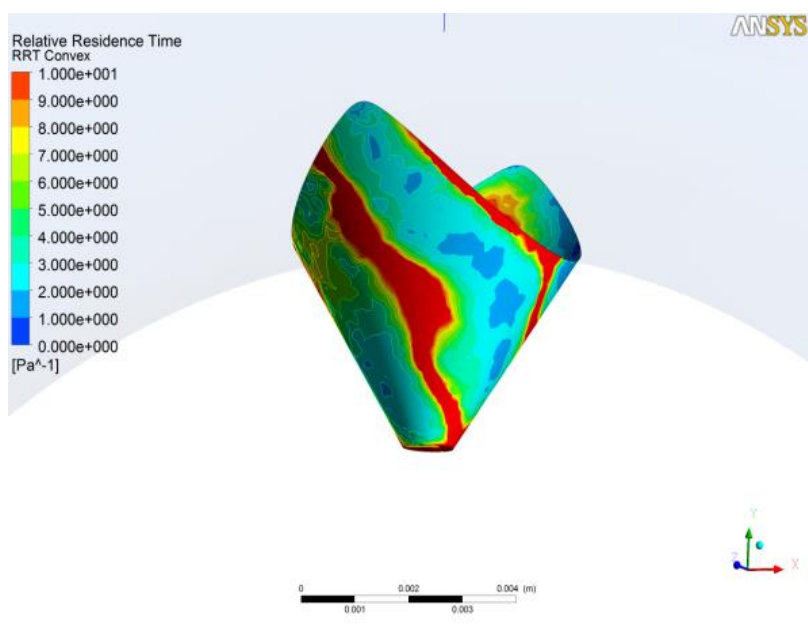

(b) Convex

Fig. 10 Time average wall shear stress (TAWSS) for both PDA closure design (a) Concave (b) Convex.

\section{CONCLUSION}

In conclusion, more flow recirculation zones with TAWSS low $(<0.5 \mathrm{~Pa})$ will enable accumulation of pro-coagulant and proinflammatory elements that contribute to thrombosis formation. Convex shape generated more low wall shear stress TAWSS $_{\text {low }}<0.5$ $\mathrm{Pa}$ ) and increase the area exposed to high oscillatory wall shear stress $(\mathrm{OSI} \geq 0.2)$ that also cause the increment of relative residence time $\left(\mathrm{RRT} \geq 10 \mathrm{~Pa}^{-1}\right)$. Compared to a concave shape, convex shape reduced the percentage of low wall shear stress $\left(\right.$ TAWSS low $_{\text {lo }}<0.5 \mathrm{~Pa}$ ) and reduced the area exposed to high oscillatory wall shear stress (OSI $\geq$ 0.2 ), which also caused the reduction of relative residence time (RRT $\geq$ $\left.10 \mathrm{~Pa}^{-1}\right)$. Hence, the convex shape of closure device meets the parameters needed, and much better than concave shape. Therefore, it can be suggested that convex shape for closure device can promote thrombosis much faster compared to a concave shape.

\section{ACKNOWLEDGEMENT}

This paper is based on work partially supported by IRU-MRUN Collaborative Research Programme (Q.J130000.3045.00M87), Universiti Teknologi Malaysia (UTM) and government of Malaysia. The authors would also like to thank Muhammad Rashidi Abdul Kadir and Muhammad Ikhwan Kori with the technical advice with regards to CFD software application. 


\section{REFERENCES}

Asakura T., Karino T. 1990. Flow patterns and spatial distribution of atherosclerotic lesions in human coronary arteries. Circ. Res. 66, $1045-$ 1066.

Bengt A., Ronnie A., Love H., Mikael M., Rahman S., Berend V. W. 2012. Computational fluid dynamics for engineers. New York. Cambridge University Press.

Benitz W. E. and Committee on Fetus and Newborn 2016. Patent ductus arteriosus in preterm infants. Pediatrics. 137(1): e20153730.

Carlgren L. E. 1959. The incidence of congenital heart disease in children born in Gothenburg 1941-1950. Br. Heart J. 21, 40-50.

Douglas J., Schneider, M. D. 2012. The patent ductus arteriosus in term infants, children, and adults. Semin Perinatol 36, 146-153.

Forbes T., Turner D. 2012. What is the optimal device for closure of a persistently patent ductus arteriosus? Prog Pediatr Cardiol 33, 125-129.

Pennati G., Belloti M., Fumero R. 1997. Mathematical modelling of the human foetal cardiovascular system based on Doppler ultrasound data. Med. Eng. Phys. 19(4), 327-335.

Haruguchi H., Teraoka S. 2003. Intimal hyperplasia and hemodynamic factors in arterial bypass and arteriovenous grafts: A review. J. Artif. Organs 6, 227-235.

Juan M. J., Peter F. D. 2009. Hemodynamically Driven Stent Strut Design. Ann Biomed Eng. 37, 1486-1494.

Krichenko A., Benson L. N., Burrows P, et al. 1989. Angiographic classification of the isolated, persistently patent ductus arteriosus and implications for percutaneous catheter occlusion. Am. J. Cardiol. 63, 877-879.

Ku D. N., Giddens D. P., Zarins C. K., Glagov S. 1985. Pulsatile flow and artherosclerosis in the human carotid bifurcation. Positive correlation between plaque location and low oscillating shear stress. Arterioscler. Thromb. Vasc. Biol. 5, 293-302.

Liddy S., Oslizlok P., Walsh K. P. 2013. Comparison of the results of transcatheter closure of patent ductus arteriosus with newer amplatzer devices. Catheter Cardiovasc Interv. 82, 253-259.

Moore J. W., Levi D. S., Moore S. D., et al. 2005. Interventional treatment of patent ductus arteriosus in 2004. Catheter. Cardiovasc. Interv. 64, 91-101.

Portsman W., Wierny L., Warnke H. 1967. Closure of persistent ductus arteriousus without thoracotomy. Ger. Med. Mon. 15, 109-203.

Vaibhavi A. S., Jayesh R. B. 2014. Flow simulation of cardiac defects to evaluate effectiveness of occlusion devices. J Med Devices 8, 020940:1-3.

Vaibhavi A. S., Jayesh R. B. 2015. Simulation of pulsatile blood flow through various cardiac defects and quantitative measurements of shunted blood volume. Procedia Mater Sci. 10, 706-713.

Vaibhavi A. S., Jayesh R. B. 2016. Mathematical modeling and simulation of an occlusion device in a blood vessel. Cardiovasc Eng Technol. 7(4), 420431.

Yingying H., Jen F. K., Subbu S. V. 2014. Biomaterials and design in occlusion devices for cardiac defects: A review. Acta Biomater. 10, 1088-1101.

Thomas K., Christian J. K., Manuela A., Eva B., Emanuela R. B. 2008. Normal values for aortic diameters in children and adolescents - assessment in vivo by contrast-enhanced CMR-angiography. J. Cardiovasc. Magn. Reson. 10: 56.

Zarins C. K., Giddens D. P., Bharadvaj B. K., Sottiurai V. S., Mabon R. F., Glagov S. 1983. Carotid bifircation artherosclerosis. Quantative correlation of pluque localization with flow velocity profiles and wall shear stress. Circ. Res. 53, 502-514. 